\title{
Water Absorption of Environment Friendly Sugar Palm Fibre Reinforced Vinyl Ester Composites at Different Fibre Arrangements
}

\author{
Sapuan SM ${ }^{2 *}$, Ammar IM11, Leman $\mathrm{Z}^{2}$ and Ishak MR \\ ${ }^{1}$ laboratory of Bio composite Technology, Institute of Tropical Forestry and Forest Products (INTROP), University Putra, Malaysia \\ 2Department of Mechanical and Manufacturing Engineering, University Putra, Malaysia \\ 3Department of Aerospace Engineering, University Putra, Malaysia
}

*Corresponding author: Sapuan SM, Department of Mechanical and Manufacturing Engineering, University Putra Malaysia, 43400 UPM Serdang, Selangor, Malaysia

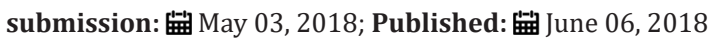

\begin{abstract}
A study on water absorption of sugar palm fibre reinforced vinyl ester (VE) composites at different fibre arrangements is presented in this paper. Hand lay-up method was used in preparing the composites and water absorption was determined using a balance and water absorption equation. Results revealed that unidirectional fibre composites demonstrate the lowest value of water absorption compared to bidirectional fibre composites $\left(0^{\circ} / 90^{\circ}\right.$ and $\pm 45^{\circ}$ fibre arrangements) but all composites showed high water absorption compared to neat VE, which may be attributed to incompatibility between fibre and matrix in composites that led to micro bubble and void.
\end{abstract}

Keywords: Fibre arrangements; Vinyl ester; Sugar palm; Water absorption; Natural fibre composites

\section{Introduction}

Research on sugar palm fibres as composite-based natural fibre was intensified in the recent years due to some advantages that they offer such as high specific properties and generally they do not pose harmful effects on the human health and the environment. It is also biodegradable and renewable. In the past, many research works had been conducted on the use of sugar palm fibres as reinforcement in polymer composites [1-4]. Water absorption is the ability of the porous materials to retain a certain amount of water in the air spaces. Water absorption of the materials determined whether or not the materials are resistance to water when they are exposed in the open environment. Compared to many natural fibres, sugar palm fibre has superior water resistant properties and it has been used in marine and outdoor application such as to make house roofs and small boat (Figure $1 \& 2$ ).

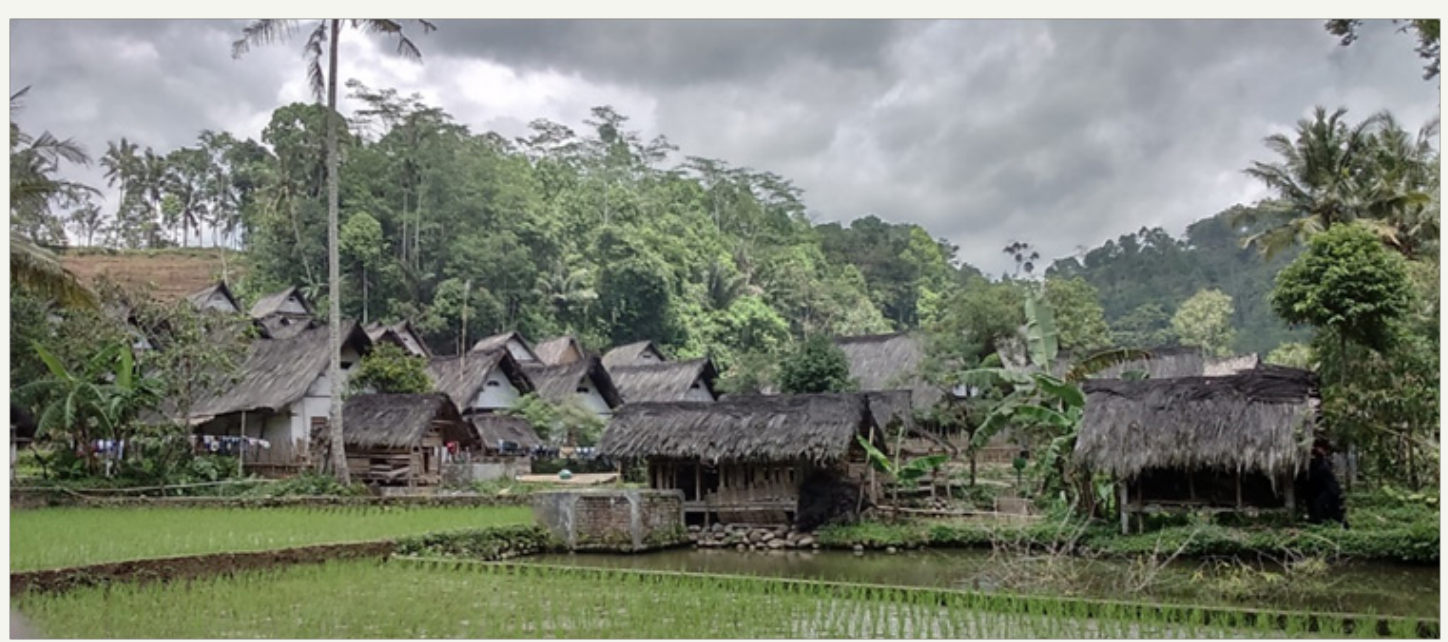

Figure 1: Houses in a village in Indonesia using roofs made from sugar palm fibres. 


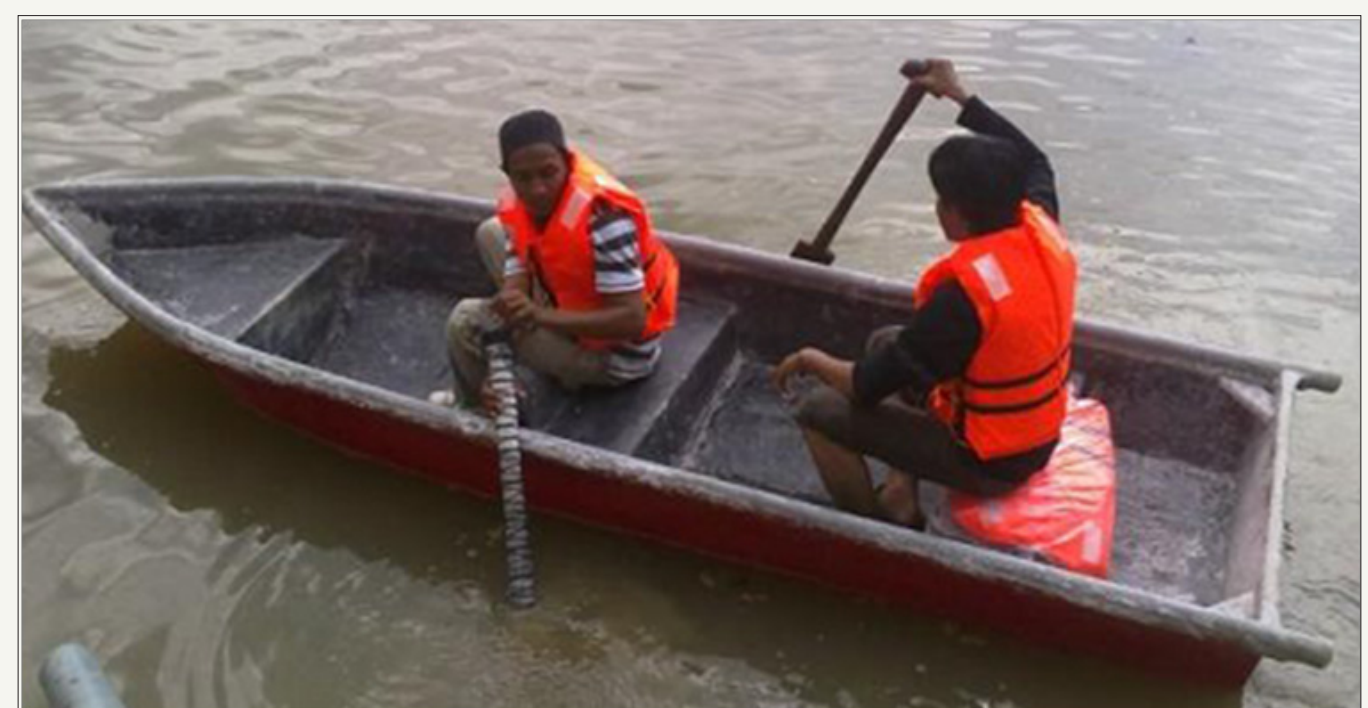

Figure 2: Sugar palm/glass fibre reinforced hybrid composite boat.

Leman et al. [5] investigated water absorption properties of sugar palm fibre reinforced epoxy composites and significant important results were obtained. Dhakal et al. [6] studied the effect of water absorption on the mechanical properties of hemp fibre reinforced unsaturated polyester composites. Specimens were immersed in a de-ionised water bath at $25{ }^{\circ} \mathrm{C}$ and $100{ }^{\circ} \mathrm{C}$ at different time durations. The percentage of water absorption

increased with the increase in fibre volume fraction in composites. Tensile and flexural properties of composites decreased while percentage moisture uptakes increased. Vilay et al. [7] used bagasse, a residue of sugarcane milling process, as reinforcement in unsaturated polyester composites and investigated its effect on fibre surface treatment and fibre loading. Fibre surface treatment using acrylic acid was better than sodium hydroxide as far as mechanical properties were concerned. Moreover, treated fibre composites show less water absorption compared to untreated fibre composites.

Water absorption of pultruded jute fibre reinforced unsaturated polyester composites were studied by Akil et al. [8]. The flexural and compression properties were found to be decreased with the increase in percentage of water uptake. Nadlene et al. [9] used roselle fibre as reinforcement for VE composites. They compared the properties of roselle fibre reinforced VE composites using silane coupling agent and alkalization as chemical treatment, with the untreated fibre reinforced VE composites. Results showed that silane coupling agent was the best chemical treatment agent in the composites in reducing water absorption. VE was used in this research as polymer matrix in sugar palm composites. VE resins are highly resistant to acids, alkalis, solvents, hypochlorites, and peroxides. It cost is comparable to polyesters and epoxies [10]. Compared to polyesters, VE resins have higher elongation to failure, which allows more load to be delivered to the reinforcement. VE is available for applications up to the temperature of $121^{\circ} \mathrm{C}$.
In this paper, an investigation of water absorption of environment friendly sugar palm fibre reinforced vinyl ester composites at different fibre arrangements is presented.

\section{Materials and Methods}

The sugar palm fibres were obtained from Kampung Kuala Jempol, Negeri Sembilan, Malaysia as reinforcement in polymer matrix composites with vinyl ester (VE) was used as matrix. VE resin, methyl ethyl ketone peroxide (MEKP), and cobalt were procured from Berjaya Bintang Timur Sdn. Bhd, in Cheras, Kuala Lumpur, Malaysia. MEKP and cobalt were used as catalyst and accelerator, respectively.

\section{Composite preparation}

The mould with the size of $150 \mathrm{~mm} \times 150 \mathrm{~mm} \times 3 \mathrm{~mm}$ was used and the method used in the fabrication process was hand lay-up process. In the current study, fibres arrangements in the composites were set in three ways; unidirectional direction $\left(0^{\circ}\right)$, in bidirectional $0^{\circ} / 90^{\circ}$ woven and $\pm 45^{\circ}$ woven arrangement. The long sugar palm fibres were soaked in tap water for 24 hours to remove the dirt from the core section. Then fibres were further washed and let dried at room temperature $\left(25-30{ }^{\circ} \mathrm{C}\right)$ for two weeks. After the fibres were completely dried, they were ready to be used in fabrication process. As stated earlier, the fibres were arranged into mould in three different arrangements. Then, the matrix was poured in the mould.

VE resin was mixed evenly with MEKP before the cobalt was added. The ratio used for mixing VE, MEKP, and cobalt was 100:2.4:1. VE and MEKP systems were made ready and cobalt was added. The mixture was stirred for about 30 seconds. Then, the mixture was poured onto the fibres already placed inside the mould. Once the mixture was fully transferred inside the mould, the mould was covered by a metal sheet. The composites were cured for 24 hours at room temperature of $25-30^{\circ} \mathrm{C}$. After the curing process, the mould was opened and the composite plates were taken out. 
From the composite plates, composite specimens were cut using a small band saw.

\section{Determination of water absorption of sugar palm fibre vinyl ester composites}

Water absorption is perceived as an increase in weight percentage in the material. The specimens were dried in an oven (time and temperature were fixed) and then placed in a desiccator to cool. The weight of each specimen was measured and recorded before and after the composites were soaked into water. The composite specimens, immersed in the water were removed and were later dried with cloth and weighed by a balance. Measurement of water absorption was expressed as a percentage loss in weight as shown in following formula:

\section{Results and Discussion}

Water absorption $(\%)=\frac{W_{2}-W_{1}}{W_{1}} \times 100$

Where,

W1 = weight of composites before being immersed into water (g)

W2 = weight of composites after being immersed into water $(g)$

Composite specimens were immersed in the water to investigate the water absorption of composites at different fibre orientations. The samples were soaked into water for 24 hours. The results of water absorption of the composites before and after soaking were collected.

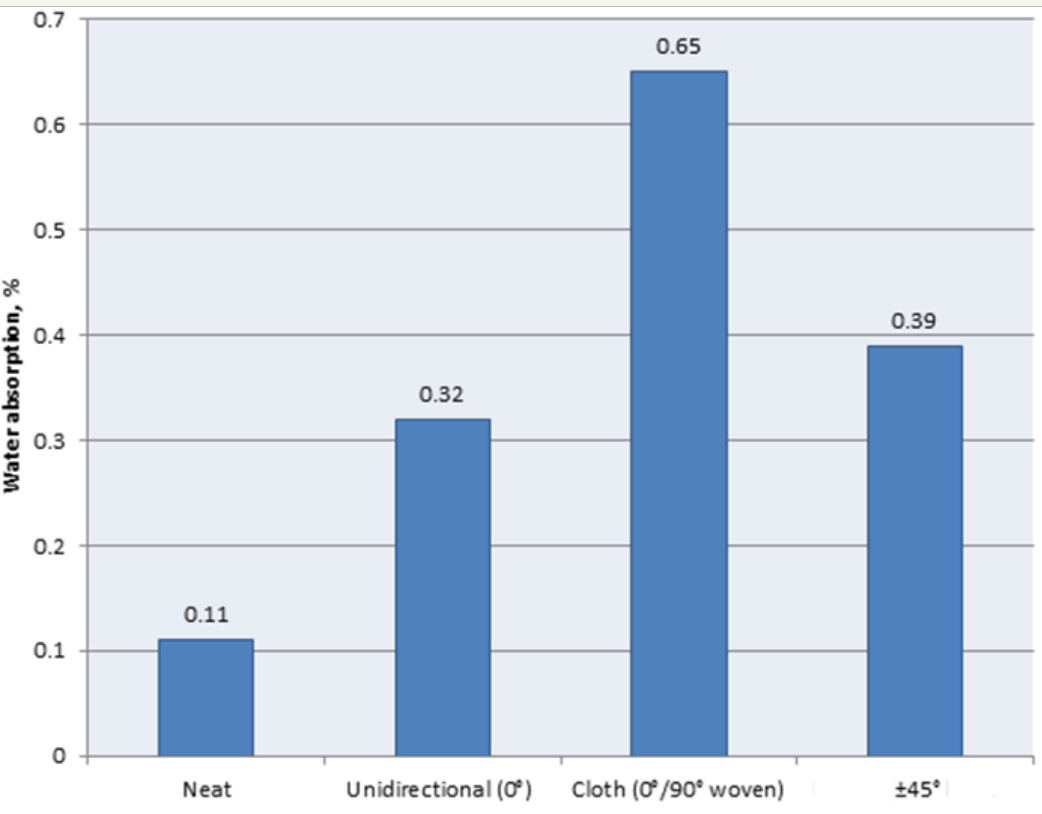

Figure 3: Average results of water absorption of sugar palm vinyl ester composites.

The experimental results of water absorption are presented in (Figure 3). The results showed that bio composites absorbed more water compared to neat VE. It was probably that sugar palm fibre is hydrophilic in nature and absorbs moisture whereas neat VE is hydrophobic, and therefore good compatibility was not achieved. Among three sugar palm VE composites investigated, unidirectional fibre composites showed the lowest water absorption (it is the most water resistant), followed by bidirectional $\pm 45^{\circ}$ and $0^{\circ} / 90^{\circ}$ cloth with the values of $0.32,0.39$, and $0.65 \%$, respectively. Although the amount of fibre loading is similar for each composite, the difference in results of water absorption is caused by different types of fibre orientation.

The factors that influenced the water absorption are type of polymer and fibre used, temperature and the exposure time. Unidirectional fibre composites showed lower water absorption than bidirectional fibre composites. For all composites, since fibre treatment was not done, incompatible fibres and matrices in fibre composites tend to generate voids at the fibre-matrix interface, which increased the free volume and more permeable [11]. Microbubbles trapped in the composites eventually became micro-void thus increased water absorption [5]. Both bidirectional fibre composites demonstrated high water absorption compared to unidirectional fibre composites. However, the study of Paplham et al. [12] showed that water absorption was independent of fibre orientation, but the fibres used were not a natural fibre but synthetic fibres.

\section{Conclusion and Recommendations}

The performance of environment friendly sugar palm fibre reinforced VE composites at different fibre arrangements were 
studied from viewpoint of water absorption. Fibre composites have high water absorption than neat VE due to presence of natural fibre. Besides, it caused by voids which have been generated from incompatible fibre and matrices. Fibre treatment is proposed in future study to enhance the compatibility of them in order to reduce water absorption of composites.

\section{Acknowledgement}

The authors wish to thank University Putra Malaysia for providing research funding for this research (Putra Grant IPBProject number GP-IPB/2014/9441500) and for Graduate Research Fellowship to the principal author during his Master of Science studies. The authors are also indebted to Ministry of Education, Malaysia, who had partially funded this research with NBOS-UCTC Community Grant, under the 8th National Blue Ocean Strategy (NBOS) to perform this research work (vote number 6234004).

\section{References}

1. Sastra HY, Siregar JP, Sapuan SM, Leman Z, Hamdan MM (2015) Flexura properties of arenga pinnata fibre reinforced epoxy composites. American Journal of Applied Sciences pp. 21-24.

2. Sahari J, Sapuan SM, Ismarrubie ZN, Rahman MZA (2012) Physical and chemical properties of different morphological parts of sugar palm fibres. Fibres and Textiles in Eastern Europe 91: 21-24.

3. Bachtiar D, Sapuan SM, Hamdan MM (2010) Flexural properties of alkaline treated sugar palm fibre reinforced epoxy composites. International Journal of Automotive and Mechanical Engineering 1: 7990.
4. Sahari J, Sapuan SM, Zainudin ES, Maleque MA (2013) Thermomechanical behaviors of thermoplastic starch derived from sugar palm tree (Arenga pinnata). Carbohydr Polym 92(2): 1711-1716.

5. Leman Z, Sapuan SM, Saifol AM, Maleque MA, Ahmad (2008) Moisture absorption behaviour of sugar palm fiber reinforced epoxy composites. Materials \& Design 29(8): 1666-1670.

6. Dhakalhn, Zhang ZY, Richardson (2007) Effect of water absorption on the mechanical properties of hemp fibre reinforced unsaturated polyester composites. Composites Science and Technology 67(7-8): 1674-1683.

7. Vilay V, Mariatti M, Mat RT, Tado M (2008) Effect of fiber surface treatment and fiber loading on the properties of bagasse fiber-reinforced unsaturated polyester composites. Composites Science and Technology 68(3-4): 631-638.

8. Akil HM, Cheng LW, Ishak ZA, Bakar AA, Rahman MA (2009) Water absorption study on pultruded jute fibre reinforced unsaturated polyester composites. Composites Science and Technology 69(11-12): 1942-1948.

9. Nadlene R, Sapuan SM, Jawaid M, Ishak MR, Yusriah L (2018) The effects of chemical treatment on the structural, thermal, physical, mechanical and morphological properties of roselle fiber-reinforced vinyl ester composites. Polymer Composites 39(1): 274-287.

10. Barbero EJ (2018) Introduction to composite materials design, ( $3^{\text {rd }}$ edn), CRC press, USA.

11. Crank J, Park GS (1968) Diffusion in polymers. Academic Press, Oxford, USA.

12. Paplham WP, Brown RA, Salin IM, Seferis JC (1995) Absorption of water in polyimide resins and composites. Applied Polymer Science 57(2): 133-137.
Creative Commons Attribution 4.0 International License

For possible submissions Click Here

\section{Submit Article}

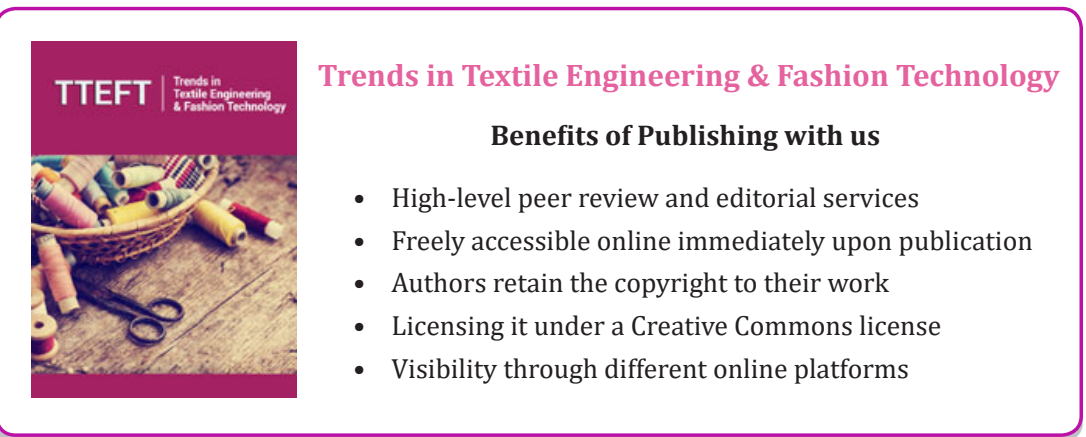

